\title{
Central Histaminergic Signaling, Neural Excitability and Epilepsy
}

\author{
Lin Yang ${ }^{1}$, Yi Wang ${ }^{1}$, and Zhong Chen ${ }^{1}$ \\ ${ }^{1}$ Zhejiang Chinese Medical University
}

December 30, 2020

\begin{abstract}
Epilepsy is a common neurological disorder characterized by repeated and spontaneous epileptic seizures, which is not well controlled by current medication. Traditional theory supports that epilepsy results from the imbalance of excitatory glutamate neurons and inhibitory GABAergic neurons. Recently, shreds of evidence from available clinical and preclinical researches suggest that histamine in the central nervous system plays an important role in the modulation of neural excitability and pathogenesis of epilepsy. Many histamine receptor ligands show positive response in animal epilepsy models, among which the H3R antagonist pitolisant even has shown a good anti-epileptic effect in clinical trials. New insights are focusing on the potential action of histamine receptors to control and treat epilepsy. This review summarizes the findings from animal and clinical researches on the role of brain histamine and histamine receptor in epilepsy. Importantly, we further provide perspectives on some possible research directions for future studies.
\end{abstract}

\section{Central Histaminergic Signaling, Neural Excitability and Epilepsy}

Lin Yang ${ }^{1}$, Yi Wang ${ }^{1,2}$, Zhong Chen ${ }^{1,2,3 *}$

${ }^{1}$ Key Laboratory of Neuropharmacology and Translational Medicine of Zhejiang Province, College of Pharmaceutical Science, Zhejiang Chinese Medical University, Hangzhou, Zhejiang, PR China

${ }^{2}$ Institute of Pharmacology \& Toxicology, College of Pharmaceutical Sciences, School of Medicine, Zhejiang University, Hangzhou, Zhejiang, PR China

${ }^{3}$ Epilepsy Center, Second Affiliated Hospital, School of Medicine, Zhejiang University, Hangzhou, Zhejiang, PR China

${ }^{*}$ Correspondence to: Prof. Zhong Chen

Tel \& Fax: +86-571-88208228.

Email address:chenzhong@zju.edu.cn

Word count (excluding abstract, reference and figure legend): 6077

Number of references: 143

Running title: Roles of histamine in epilepsy

\section{Abstract}

Epilepsy is a common neurological disorder characterized by repeated and spontaneous epileptic seizures, which is not well controlled by current medication. Traditional theory supports that epilepsy results from the imbalance of excitatory glutamate neurons and inhibitory GABAergic neurons. Recently, shreds of evidence from available clinical and preclinical researches suggest that histamine in the central nervous system plays an important role in the modulation of neural excitability and pathogenesis of epilepsy. Many histamine receptor 
ligands show positive response in animal epilepsy models, among which the H3R antagonist pitolisant even has shown a good anti-epileptic effect in clinical trials. New insights are focusing on the potential action of histamine receptors to control and treat epilepsy. This review summarizes the findings from animal and clinical researches on the role of brain histamine and histamine receptor in epilepsy. Importantly, we further provide perspectives on some possible research directions for future studies.

Keywords: epilepsy, histamine, histamine receptor, central nervous system

\section{Abbreviations}

AA, arachidonic acid; ADD, afterdischarge duration; AC, adenylate cyclase; AEDs, anti-epileptic drugs; AGS, audiogenic seizure; ASP, Anticonvulsant Screening Program; cGMP, cyclic guanosine monophosphate; CNS, central nervous system; CREB, cAMP response element-binding; DAG, diacylglycerol; DBS: deep brain stimulation; DRE, drug-resistant epilepsy; EL, epilepsy like; ERK, extracellular signal-regulated kinase; GSK3 $\beta$, glycogen synthase kinase $3 \beta \cdot \mathrm{HCN}$, hyperpolarization-activated cyclic nucleotide-gated; HDC, histidine-decarboxylase; HFS, high-frequency stimulation; HNMT, histamine N-methyltransferase; H1R, histamine $\mathrm{H} 1$ receptor; H2R, histamine $\mathrm{H} 2$ receptor; H3R, histamine $\mathrm{H} 3$ receptor; H4R, histamine H4 receptor; $\mathrm{IP}_{3}$, phosphatidyl inositol-4, 5-biphosphate; KA, Kainic acid; KM, Krushinski-Molodkina; KO, knock out; LFS, low-frequency stimulation; MAPK, mitogen-activated protein kinase; MES, maximal electroshock seizure; MTLE, mesial temporal lobe epilepsy; NINDS/NIH, National Institute of Neurological Disorders and Stroke/National Institutes of Health; PLA2, phospholipase A2; PKA, phosphokinase A; PKC, phosphokinase C; PTZ, pentylenetetrazole; RGC, retrosplenial granular cortex; STR, strychnine; TMN, tuberomammillary nucleus; VMAT-2, Vesicular monoamine transporter-2; WT, wide type

\section{Introduction}

Epilepsy is one kind of common neurologic disease, affecting up to 70 million people worldwide (Trinka, Kwan, Lee \& Dash, 2019). Anti-epileptic drugs (AEDs) are the first choice for most patients. Even so, the adverse effects of AEDs lead to improper seizure control of many patients. What's worse, there is approximately one-third of patients become drug-resistant epilepsy (DRE) (Löscher, Klitgaard, Twyman \& Schmidt, 2013). For DRE, surgery is the ultimate therapy but less than $1 \%$ of patients preferred (Engel, 2018). Alternative treatments, such as deep brain stimulation (DBS), laser interstitial thermal therapy, vagus nerve stimulation and dietary modification, are also used for epilepsy treatment (Kaeberle, 2018; Schaper et al., 2020), but anti-epileptic effects are limited. Above therapeutic challenge in clinical may be due to the fact that the mechanism of epilepsy is not fully understood. Traditional theory supports that epilepsy results from the imbalance of neural excitability. Classically, researches mainly focus on the excitatory glutamatergic neurotransmission and inhibitory GABAergic neurotransmission, both of which are the designed target of most of AEDs.

Pieces of evidence have indicated that other neurontransmitters, including histamine, 5-HT, and acetylcholine, also participating in the modulation of neural excitability and the ictogenesis and epileptogenesis (Meller, Brandt, Theilmann, Klein \& Löscher, 2019; Sugitate, Okubo, Nariai \& Matsui, 2020; Zhao, Lin, Chen, Li \& Huo, 2018). Among them, histamine has been the least understood. Histamine was firstly isolated from the brain cortex by Kwiatkowski in 1943 (Kwiatkowski, 1943). Since then several studies have demonstrated that histamine acts as a neurotransmitter in the brain (Haas, Sergeeva \& Selbach, 2008). A decline of histamine content has been found in temporal neocortex of patients with pharmacoresistant mesial temporal lobe epilepsy (MTLE) (Bañuelos-Cabrera et al., 2016). Indeed, several H3R ligands have been discovered to target the epileptic treatment (Sadek, Saad, Sadeq, Jalal \& Stark, 2016). This review summarizes the role of histamine and its receptors in neural excitability and epilepsy, and further provides perspectives on future research directions.

\section{Histamine and neural excitability}

2.1 Histamine and histamine receptors in the brain

The histaminergic neuron is the main source of histamine production in the brain, whose soma is located 
in the tuberomammillary nucleus (TMN) of the hypothalamus. The histaminergic neuron fibers are widely distributed in the brain. Neuronal histamine is stored in cell somata and especially in axon varicosities (Haas, Sergeeva \& Selbach, 2008). Besides neurons, one study found that cultured microglia also could synthesize histamine (Katoh et al., 2001), while the production of histamine in cerebrovascular endothelial cells is still controversial (Karlstedt et al., 1999; Yamakami et al., 2000). In the peripheral connective tissue, histamine is synthesized and released from mast cells and basophils, which is closely associated with immune response. Stomach enterochromaffin-like cells also give rise to the release of histamine to regulate gastric acid secretion. Interestingly, under some pathological conditions, mast cells can enter the brain. Distinct sources of histamine are shown in Fig.1.

The dietary amino acid L-histidine taken up into neurons by L-amino acid transporter was catalyzed by histidine-decarboxylase (HDC) into histamine by decarboxylation. Neuronal histamine was packaged into vesicles through vesicular monoamine transporter-2 (VMAT-2), and calcium release evokes histamine release from vesicles upon the histaminergic neuron depolarization (Erickson, Schafer, Bonner, Eiden \& Weihe, 1996). Then neuronal histamine release into the postsynaptic cleft, which is metabolized into tele-methyhistamine by histamine $N$-methyltransferase (HNMT) and then degraded into $N^{l}$-methylimidazole acetic acid by monoamine oxidase B (Fig.1). Brain histamine modulates several physiological and pathological processes, including sleep-wake cycle, water and food intake, locomotion, neuroendocrine regulation, attention, learning and memory, epilepsy and so on (Sadek, Saad, Sadeq, Jalal \& Stark, 2016). There are four histamine receptors have been identified in the brain: histamine $\mathrm{H} 1, \mathrm{H} 2, \mathrm{H} 3$, and $\mathrm{H} 4$ receptors (H1R, H2R, H3R, and H4R). H1R and H2R were postsynaptically located, H3R was both presynaptically and postsynaptically located. It is still controversial that whether H4R is expressed in neurons.

\section{$2.2 \mathrm{H} 1 \mathrm{R}$ and neural excitability}

The human H1R gene is located on chromosome 3, which encodes a member of the 7-transmembrane, Gprotein-associated receptor family (486-491 amino-acids). H1R is coupled with Gq/11 protein and phospholipase $\mathrm{C}$, which in turn hydrolyses phosphatidyl-4, 5-biphosphate to form second messenger, diacylglycerol (DAG) and phosphatidyl inositol-4, 5-biphosphate ( $\mathrm{IP}_{3}$ (Leurs, Traiffort, Arrang, Tardivel-Lacombe, Ruat \& Schwartz, 1994). DAG activates phosphokinase C (PKC), which in turn induces mitogen-activated protein kinase (MAPK) activation, which involves in neuron synaptic plasticity (Yamamoto et al., 2012). The DAG and $\mathrm{IP}_{3}$ promote calcium release from the endoplasmic reticulum into the cytoplasm. In addition, H1R activation subsequently leads to formation of arachidonic acid (AA) and cyclic guanosine monophosphate (cGMP). The H1R is widely distributed in the brain, including thalamus, cortex, basal forebrain, raphe nuclei, hypothalamus, septal nuclei, amygdala, hippocampus, locus corelus, nucleus accumbens, and nucleus tractus solitaries as well as cerebellum. The central H1R is mainly corresponding for the side effects of antihistamine drugs.

Most of H1R mediates either excitatory or inhibitory response of histamine in neurons, depending on different brain regions. For example, through H1R, histamine elicits neuronal excitability in the ventromedial hypothalamus and GABAergic neurons in both substantia nigra and ventral tegmental area, and the $\mathrm{K}^{+}$ channel is involved in that (Korotkova, Haas \& Brown, 2002; Zhou, Lee, Devidze, Zhang, Kow \& Pfaff, 2007). However, H1R also negatively regulate the neuronal excitability. For instance, H1R decreases cell excitability of hippocampal pyramidal neurons through activation of $\mathrm{K}^{+}$channels by increase of $\mathrm{Ca}^{2+}$ (Selbach, Brown \& Haas, 1997). Similarly, H1R antagonist led to membrane potential depolarization in superior cervical ganglion neurons via inhibiting KCNQ/M K ${ }^{+}$channel (Liu, Zhang, Wang, Zhang \& Zhang, 2008).

\section{$2.3 \mathrm{H} 2 \mathrm{R}$ and neural excitability}

The human H2R gene is located on chromosome 5, encoding 7-transmembrane G-protein coupled receptor (359 amino-acids) (Traiffort, Vizuete, Tardivel-Lacombe, Souil, Schwartz \& Ruat, 1995). The H2R is coupled to Gs G-protein, which in turn activates adenylyl cyclase to form a second messenger cAMP. Then cAMP activates phosphokinase A (PKA), which in turn phosphorylates downstream targets, such as cAMP response element-binding (CREB) protein. Similar to H1R, the distribution of H2R in the brain is wide, 
including cortex, basal ganglia, hippocampus, amygdala, thalamus, and hypothalamus. The H1R and H2R are colocalized in hippocampus, locus coeruleus, raphe nuclei, substantia nigra and ventral tegmental area.

H2R mainly mediates the neuronal excitability elicited by histamine. Histamine induced excitatory response in globus pallidus neurons and cerebellar dentate nucleus neurons, as well as cerebellar Purkinje cells through H2 receptors (Chen, Wang, Yung, Chan \& Chow, 2005; Qin et al., 2011; Tian, Wen, Li, Zuo \& Wang, 2000), which linked to intracellular G-protein-adenylate cyclase (AC)- PKA signaling pathway (Chen, Wang, Yung, Chan \& Chow, 2005). Additionally, histamine elicits excitatory response in the lateral vestibular nucleus neurons in rats, which is co-mediated by the H2R linked-hyperpolarization-activated cyclic nucleotide-gated (HCN) channels and $\mathrm{K}^{+}$channels (Li et al., 2016).

Many studies have confirmed that activation of both postsynaptic H1R and H2R co-mediates histamine induced-neuron excitability in several kinds of neurons. For instance, histamine excites dopamine D1 and D2 receptor-expressing striatal GABAergic medium spiny projection neurons, nucleus basalis cholinergic neurons, substantia nigra pars reticulate inhibitory projection neurons, GABAergic ventral pallidum neurons, superior vestibular nuclear neurons, and inferior vestibular nucleus neurons via postsynaptic H1R and H2R (Ji et al., 2018; Khateb, Fort, Pegna, Jones \& Mühlethaler, 1995; Peng, Zhuang, He, Zhu \& Wang, 2013; Zhou, Xu, Zhao, LeDoux \& Zhou, 2006; Zhuang, Wu, Wu, Zhu \& Wang, 2013; Zhuang et al., 2018). In medial vestibular nuclear neurons, histamine induces strong postsynaptic excitatory action by $\mathrm{Na}+-\mathrm{Ca}^{2}+$ exchangers coupled to H1R and HCN linked to H2R (Zhang, Yu, Zhuang, Peng, Zhu \& Wang, 2013). Additionally, histamine facilitates GABAergic transmission in the rat entorhinal cortex through H1R and $\mathrm{H} 2 \mathrm{R}$ by activating $\mathrm{Na}^{+}$permeable cation channels and inhibiting inward rectifier $\mathrm{K}^{+}$channels (Cilz \& Lei, 2017).

\section{$2.4 \mathrm{H} 3 \mathrm{R}$ and neural excitability}

The human H3R gene is located on chromosome 20, encoding $\mathrm{G}_{\mathrm{i} / \mathrm{o}}$-protein coupled receptor (326-445 aminoacids) (Arrang, Garbarg \& Schwartz, 1983). The distribution of H3R has been found in cerebral cortex, nucleus accumbens, striatum, olfactory tubercles and substantia nigra, hippocampus, and hypothalamus. The H3R is located on the soma, axon, dendrites, and varicosities of histaminergic neurons, as well as the axon of non-histaminergic neurons (Stevens, Eriksson, Brown \& Haas, 2001). Additionally, it has been found that H3R is located on endothelial cells. The H3R mainly located presynaptically is identified as the autoreceptor to regulate the synthesis and release of histamine in histaminergic neurons and acts as heteroreceptor to regulate other neurotransmitters in non-histaminergic neurons. H3R activation inhibits the calcium channels (Lundius, Sanchez-Alavez, Ghochani, Klaus \& Tabarean, 2010), and activates the inwardly-rectifying potassium channels blocking nerve depolarization (De Luca et al., 2016), which inhibits the synthesis and release of histamine and other neurotransmitters, including glutamate, GABA, noradrenaline, dopamine, acetylcholine, and serotonin. The H3R also inhibits AA to form cAMP (Lovenberg et al., 1999), activates MAPK, Akt/glycogen synthase kinase $3 \beta$ (GSK3 $\beta$ ) and phospholipase A2 (PLA2) (Giovannini et al., 2003; Sadek, Saad, Sadeq, Jalal \& Stark, 2016). Apart from presynaptic location, it has been reported H3R also present on postsynaptic location in basal ganglia colocalized with dopamine receptor 1 and 2 (Ellenbroek \& Ghiabi, 2014).

H3R plays a complex role in the modulation of neural excitability, depending on the targeted neurotransmitter. Histamine inhibits spontaneous GABA release from presynaptic nerve terminals projecting to ventromedial hypothalamic neurons by inhibiting presynaptic $\mathrm{P} / \mathrm{Q}$-type $\mathrm{Ca}^{2+}$ channels via a G-protein coupled to H3R and this may modulate the excitability of ventromedial hypothalamic neurons (Jang, Rhee, Watanabe, Akaike \& Akaike, 2001). H3R reduces the coupling of fast excitatory postsynaptic field potentials to population spikes of hippocampal dentate gyrus granule cells (Varaschin, Rosenberg, Hamilton \& Savage, 2014), and inhibits the TMN histaminergic neurons and substantia nigra pars reticulate inhibitory neuron (De Luca et al., 2016; Zhou, Xu, Zhao, LeDoux \& Zhou, 2006). It needs to be noted that histamine reduces the excitatory gain of D1-expressing medium spiny neurons in nucleus accumbens core by H3R dependent long-term depression through $\mathrm{G}_{\beta \gamma}$-Akt/GSK3 $\beta$ signaling pathway (Manz, Becker, Grueter \& Grueter, 2020). 
Since H3R discovery, there are kinds of research focus on the drug discovery of these ligands (Szczepanska, Kuder \& Kiec-Kononowicz, 2018). Agonists or antagonists target H1R/H2R/H3R or H1R/H2R/H3R knock out (KO) mice are commonly used to study the function of these receptors in the brain (Schneider, Neumann \& Seifert, 2014; Toyota et al., 2002).

\section{$2.5 \mathrm{H} 4 \mathrm{R}$ and neural excitability}

The H4R is recently discovered in the last decades, which is mainly located in microglia in the central nervous system (CNS) (Connelly et al., 2009; Raible, Lenahan, Fayvilevich, Kosinski \& Schulman, 1994). At present, it is controversial whether the expression of H4R is on neurons or not (Connelly et al., 2009; Schneider \& Seifert, 2016). The human H4R gene is located on chromosome 18, similar to H3R, which is coupled to $\mathrm{G}_{\mathrm{i} / \mathrm{o}^{-}}$ protein coupled receptor (Cogé, Guénin, Rique, Boutin \& Galizzi, 2001). In the brain, H4R was distributed in the dorsal root ganglia, hippocampus, and cerebral cortex (Yuan \& Silberstein, 2018). Similar to other histamine receptors, H4R increases calcium release (Li, Carozza, Shatos, Hodges \& Dartt, 2012), which is crucial for regulating neuron synaptic excitability (Carrasco, Jaimovich, Kemmerling \& Hidalgo, 2004).

Activation of H4R leads to inhibition of CREB in the cerebellar vermis and prefrontal cortex (Fernandes \& Serafim, 2019). Also, H4R targets and inactivates the downstream extracellular signal-regulated kinase (ERK)-CREB pathway (Sanna, Mello, Masini \& Galeotti, 2018). H4R antagonists inhibit vestibular neuron activity (Desmadryl et al., 2012), suggests H4R involves in vestibular neuron excitability. Agonists or antagonists target H4R are commonly used to assess the function of H4R in some behavioral and disease phenotypes (Fernandes \& Serafim, 2019; Fernandes, Serafim, Gianlorenco \& Mattioli, 2017; Sanna, Borgonetti, Masini \& Galeotti, 2020; Zhou et al., 2019). Recently years, H4R KO mice were also applied to investigate the behavioral phenotype and its neural function (Sanna, Ghelardini, Thurmond, Masini \& Galeotti, 2017).

\section{Histamine and its receptors in clinical research for epilepsy}

As we mainly mentioned the histamine and its receptors in regulating the neuronal excitability, it is not surprise that histamine would play a role in epilepsy that mainly due to the imbalance of "excitationinhibition". Next, we address the action of histamine and its receptors in epilepsy in clinical studies and the effect of related ligands targeting the histamine receptor on epilepsy in preclinical trials that are summarized in Table 1.

In 1993, Yokoyama reported a 5-years-old boy increased the number of epileptic discharges after administration of d-chlorpheniramine (H1R antagonist) (Yokoyama, Iinuma, Yanai, Watanabe, Sakurai \& Onodera, 1993). Since then, similar evidence has been observed in two 4 and 5 months old infancy, who developed tonic spasm after taking H1R antagonist ketotifen (Yasuhara, Ochi, Harada \& Kobayashi, 1998). In children, case report indicated that uptake H1R antagonist desloratadine to treat atopic dermatitis, who develop absence seizure with typical electroencephalogram pathological pattern or idiopathic generalized epilepsy later (Cerminara, El-Malhany, Roberto, Lo Castro \& Curatolo, 2013). More seriously, overdose taking the H1R antagonist diphenhydramine or ketotifen developed generalized tonic-clonic seizures and dysrhythmias in a teenager, or even toxic encephalopathy followed by localization-related epilepsy and mild mental retardation in infancy (Labarinas, Meulmester, Greene, Thomas, Virk \& Erkonen, 2018; Yokoyama, Hirose, Uematsu, Haginoya, Iinuma \& Kimura, 2012). The above findings demonstrated that the H1R antagonist has a pro-seizure effect, especially in case of overtaking.

Except for the action of H1R antagonist, the patient after uptake H2R antagonist also affects epilepsy. For example, a patient treated with famotidine (H2R antagonist) for gastric pain, then presented manic symptoms and developed two generalized seizures after the famotidine was discontinued (von Einsiedel, Roesch-Ely, Diebold, Sartor, Mundt \& Bergemann, 2002). However, a larger observational cohort study showed that the use of $\mathrm{H} 2 \mathrm{R}$ antagonist was not associated with an increased risk of seizures in the overall population or the cohorts stratified by epilepsy status, which including 8605 patients with seizure compared with 40000 controls (Sáez, González-Pérez, Gaist, Johansson, Nagy \& García Rodríguez, 2016). It seems that $\mathrm{H} 2 \mathrm{R}$ antagonist might not affect the risk of seizure. However, these findings are not direct evidence that could confirm that the effect of central H1R or H2R on epilepsy. 
Autopsy reports could provide more direct evidence for the role of histamine and its receptor in epilepsy. However, related studies are limited. At present, there is only one literature reported that patients with MTLE showed a reduction in the H3R function in the hippocampus, and high efficacy of H3Rs Gai/o protein activation with low tissue contents of histamine in temporal cortex, which suggests the potential protective role of H3R and histamine in MTLE (Bañuelos-Cabrera et al., 2016). Most studies focus on identifying the role of H1R or H2R antagonist in epilepsy. More direct evidence from clinical studies is needed.

Based on the specific high constitutive activity of H3R, the H3R antagonists receive a lot of attention. Many H3R antagonist ligands show a good protective effect on epilepsy in preclinical studies, which we will discuss later. Antagonists of H3R are classified into imidazole-based and non-imidazole-based antagonists. The latter has high selectivity and affinity. The H3R antagonist, pitolisant shows good anti-epileptic effects in clinical. One third of patients received the positive response in phase II and pitolisant suppressed the generalized photoparoxysmal response of all epilepsy patients in the photosensitivity proof of concept model in early phase II clinical trials (Collart Dutilleul et al., 2016; Kasteleijn-Nolst Trenité, Parain, Genton, Masnou, Schwartz \& Hirsch, 2013). Currently, pitolisant (WakixR) was approved by the European Commission for the treatment of narcolepsy in March 2016. There are several other H3R antagonists ligands under clinical development for other target indications but not epilepsy (Harwell \& Fasinu, 2020). At present, most available clinical researches mainly focus on the effect of histamine receptor-related ligands, especially H1R, H2R, and H3R. Little is known about that the role of H4R in epilepsy from clinical studies. However, how the histamine content change in the subdivide brain, or the distribution change of histamine receptor subtypes, needs to validate further.

\section{Histamine and its receptors in animal studies for epilepsy}

There are many limitations to clinical researches. Animal models of epileptic seizures have an indispensable role in the advancement of investigating the causal role of histamine and its receptor in epilepsy, have been instrumental in the preclinical development of new antiepileptic agents. The models of epilepsy or seizures can be classified into genetic animal models and acquired animal models. For the former, it includes transgenic mice with spontaneous recurrent seizures, and animals with reflex seizure, such as DBA/2 mice, GEPR, and Krushinski-Molodkina (KM) animals. For the latter, there are usually two common ways to induce seizures in normal animals: electrical induction and chemical induction. Pentylenetetrazole (PTZ), pilocarpine (Ach M receptor agonist), strychnine (STR), kainic acid (KA, glutamate receptors agonists), and picrotoxin $\left(\mathrm{GABA}_{\mathrm{A}}\right.$ receptor antagonist) are commonly used chemical substance to induce seizure. Maximal electroshock seizure (MES), amygdaloid kindling, 6-Hz stimulation and transauricular kindling are commonly used as electrical induction method of seizure. Besides, except for the electrical and chemical indication of seizures in normal animals, there are other seizure-induced models, such as audiogenic stimulation, vestibular stimulation and hyperthermia-induced febrile seizure (Löscher, 2011; Potschka, 2012). Actually, the electrical and chemical induction methods are combined use together in some cases. Next, we summarize findings of changes in histamine level or histamine receptor expression in across chemically and electrically-induced epilepsy animal models, as well as other animal models (Table 2). Moreover, we also pay attention to review the therapeutic effect of histamine or histamine receptors related ligands on epilepsy (Table 3), and genetic interventions, especially genetic-edited animal, as well as other interventions in epilepsy in animal researches. The change of histamine and histamine receptor and the therapeutics effect of histamine related ligands in epilepsy are showed in Fig.2.

\subsection{The change of central histaminergic signaling in epilepsy animal models}

In the PTZ-induced generalized myoclonic seizures, most studies found that PTZ induced seizure accompanied by a decrease of histamine in the hippocampus, thalamus, and hypothalamus (Alachkar et al., 2020; Chen, Ren, Zhang \& Hu, 2012; Singh, Pillai \& Mehndiratta, 2014; Zhang, Chen, Chen, He \& Hu, 2017; Zhang, Ma \& Li, 2006), while no change of histamine in hippocampus and striatum also has been found (Szyndler et al., 2006). A similar phenomenon has been observed in MES-induced generalized tonic-clonic seizures: histamine decreased in the cortex, hippocampus, brainstem and hypothalamus, without changing glutamate and GABA levels in the TMN E2-region lesion rats (Jin et al., 2007). Moreover, it has been found 
that histamine content was decreased in amygdala of amygdala kindling-induced focal seizure with secondary generalized seizure (Kamei, Ishizawa, Kakinoki \& Fukunaga, 1998). Besides, a reduction of brain histamine level has been found in transauricular kindling rats ( $\mathrm{Li}$, Liu, Zhu, Zhou \& Chen, 2006), and 6-Hz stimulation mice (Jahan, Pillai \& Vohora, 2017). In the audiogenic DBA/2 mice, a decrease of histamine level has been detected in the hypothalamus (Tuomisto, Sturman, Freeman \& Tarhanen, 2003). And a decrease of blood histamine level has been found that hyperthermia-induced convulsion in infant rats (Gholipoor, Saboory, Roshan-Milani \& Fereidoni, 2013). Histamine levels in the striatum, hippocampus, amygdala, midbrain, thalamus and hypothalamus of genetically epilepsy-prone KM rats were significantly lower than epilepsy resistant Wistar rats (Onodera, Tuomisto, Tacke \& Airaksinen, 1992). However, in the KA-induced temporal lobe epilepsy, KA immediately increases brain histamine and histamine immunoreactive nerve fibers in the piriform cortex, amygdala, hippocampus and striatum after KA injection 6 hours later (Lintunen, Sallmen, Karlstedt \& Panula, 2005). The reduction of histamine content observed in many brain regions across focal seizure and generalized seizures, suggesting that histamine involves in the pathological process of epilepsy. However, it is still unclear how histamine content change in the different stage of epilepsy.

In histamine receptor level, only H1R and H3R have been found change in epilepsy model. The mRNA expression of H1R transiently decreases in the midline areas and the ventral thalamus, and the mRNA expression of H3R isoforms with a full-length third intracellular loop firstly transiently decrease and increase after 1 week in the ventral posterior, posterior, and geniculate nuclei in the KA model (Jin, Lintunen \& Panula, 2005). However, another research reported that KA transiently (after KA injection 6, 12 and 24 hours) increases brain mRNA of H3R isoforms with a full-length third intracellular loop in the hippocampal CA3, followed by piriform cortex and amygdala and then the hippocampal CA1 area (Lintunen, Sallmen, Karlstedt \& Panula, 2005). Likewise, the H1R density increases in superior colliculus, central grey, nucleus interpositus and pontine nuclei in the genetic epilepsy-prone WAG/Rij rats (Midzyanovskaya \& Tuomisto, 2003). The difference outcome between the former two studies may be caused by different sampling times and different brain regions. For the expression of histamine receptor under epilepsy, more researches are needed to elucidate the changes of histamine receptors, especially H2R and H4R.

4.2 The therapeutics effect of ligands targeting histamine and histamine receptors on epilepsy in animal model

There are several studies investigating the protective effects of histamine in epilepsy. The histamine precursor, carnosine and histidine showed a protective effect on PTZ kindling rat indicating by seizure onset delay, seizure stage decrease, as well as prolonging latency to myoclonic jerks (Chen, Li, Zhu, Shen \& Wei, 2002; Zhang, Shen, Jin, Hu, Zhao \& Chen, 2004). Similarly, histidine and histamine inhibit seizure in amygdala kindling rats (Ago, Ishikawa, Matsumoto, Ashequr Rahman \& Kamei, 2006; Kamei, Ishizawa, Kakinoki \& Fukunaga, 1998), audiogenic seizure (AGS) in GEPR-9s rats (Feng \& Faingold, 2000; Feng, Naritoku, Randall \& Faingold, 2001), and rhythmic vestibular stimulation epilepsy like mice (Yawata, Tanaka, Nakagawa, Watanabe, Murashima \& Nakano, 2004), this effect is attenuated by H1R antagonist, pyrimidine, diphenhydramine and chlorpheiramine (Ago, Ishikawa, Matsumoto, Ashequr Rahman \& Kamei, 2006; Kamei, Ishizawa, Kakinoki \& Fukunaga, 1998), suggesting H1R medicates anti-seizure effect of histamine. However, Yoshida reported that L-histidine did not reduce seizure ranks and afterdischarge duration (ADD) in amygdaloid kindling rats (Yoshida, Noguchi \& Tsuru, 2000). This may be due to the fact that the action of histidine will be affect by its administration dosage. For example, L-histidine prolonged the latency to the onset of bilateral forelimb clonus, without changing the seizure stages and ADD, however, daily treatment of L-histidine facilitated the seizure development (Wada, Shiraishi, Nakamura \& Koshino, 1996). Ligands inhibiting the HNMT (thus increasing the brain histamine content), metoprine decreased the seizure stage in amygdala kindling rats and delayed the seizure onset in epileptic-like mice after the vestibular stimulation (Kamei, Ishizawa, Kakinoki \& Fukunaga, 1998; Yawata, Tanaka, Nakagawa, Watanabe, Murashima \& Nakano, 2004). In addition, metoprine decreased the duration and severity of clonic-tonic convulsions induced by AGS in KM rats and suppressed the spike wave discharge in WAG/Rij rats (Samotaeva, Birioukova, Midzyanovskaya, Kuznetsova, Bazyan \& Tuomisto, 2012; Vinogradova, Shatskova \& Tuomisto, 2007). These researches suggest preventing histamine degradation could effectively protect against epilepsy. 
Next, we discuss the therapeutic effect of several H1R antagonists, including antazoline, cetirizine, chlorpheniramine, cyproheptadine, diphenhydramine, epinastine, ketotifen, loratadine, mepyramine, pyrilamine and triprolidine. In the MES-induced seizure model, antazoline, ketotifen, diphenhydramine, chlorpheniramine, and cyproheptadine show varying degrees of anti-seizure effects in adult mice or 3 weeks infant rats (Ishikawa et al., 2007; Swiader, Wielosz \& Czuczwar, 2004), however, the ketotifen accelerates seizure in infant rats has been found in MES-induced seizure model (Yamada, Takizawa, Tamura \& Kanda, 2012). The controversial outcome of ketotifen in MES infant rats, might due to the different dosage: orally administrated 5 or $10 \mathrm{mg} / \mathrm{kg}$ leading positive effect, whereas large dose $30 \mathrm{mg} / \mathrm{kg}$ showing the opposite. Similarly, opposite outcomes of H1R antagonists manifesting in the rhythmic vestibular stimulation epilepsy like mice, diphenhydramine at a dosage of $15 \mathrm{mg} / \mathrm{kg}$ accelerated this process (Yawata, Tanaka, Nakagawa, Watanabe, Murashima \& Nakano, 2004), whereas, diphenhydramine at $30 \mathrm{mg} / \mathrm{kg}$ delayed the convulsive seizure induction (Sturman, Freeman \& Quinn, 2001). Besides, the H1R antagonist, pyrilamine, ketotifen and diphenhydramine, but not epinastine, loratadine and cetirizine, accelerates seizures in amygdala kindling model (Fujii, Tanaka, Harada, Hirai \& Kamei, 2003; Yokoyama, Sato, Iinuma, Onodera \& Watanabe, 1996). Additionally, another H1R antagonist, triprolidine increased seizures severity and neuronal damage in the septum, thalamus, CA3 region of the hippocampus, and retrosplenial granular cortex (RGC) in the KA-treated immature mice (Kukko-Lukjanov et al., 2010). Interestingly, the H1R antagonist ketotifen possessed a biphasic action, acutely it enhanced the anticonvulsant action of carbamazepine and phenobarbital while, following 7-day treatment, reduced the antiseizure activity of carbamazepine in MES (Swiader, Wielosz \& Czuczwar, 2004). These findings demonstrate the controversial therapeutic effect of H1R antagonist in epilepsy, and the dosage of H1R antagonists might contribute that.

Reports about the ligands targeting H2R in epilepsy are limited. One study showed that an H2R agonist, amthamine decreased clonic-tonic seizure in picrotoxin-induced and PTZ-induced epilepsy mice model (Seeley \& Sturman, 2001). Another reported that cimetidine, an H2R antagonist, given alone either acutely or chronically did not alter PTZ-induced seizure and also did not affect the anticonvulsant properties of AEDs, such as valproate, clonazepam or phenobarbital in PTZ model. (Swiader, Porebiak, Swiader, Wielosz \& Czuczwar, 2006). Although potential positive therapeutics obtained from H2R agonist, systemic investigations are urge to reveal the role of H2R in epilepsy.

Up to date, many H3R ligands have been synthesis to target epilepsy. H3R antagonist, clobenpropit, thioperamide, and E177 delayed seizure onset, seizure stage, and prolonged the latency to myoclonic jerks and clonic generalized seizure in PTZ-induced seizure model (Alachkar et al., 2020; Zhang et al., 2003; Zhang, Chen, Chen, Hu \& Ding, 2013; Zhang, Shen, Jin, Hu, Zhao \& Chen, 2004). Similar to PTZ model, there are many H3R antagonist ligand, including thioperamide, iodophenpropit, AQ0145, clobenpropit, VUF5514, VUF5515 and VUF4929 decreased seizure stage in amygdala kindling model, except AQ0145, all ligands also showed protective effect in MES model (Harada, Fujii, Hirai, Shinomiya \& Kamei, 2004; Harada, Hirai, Fujii, Harusawa, Kurihara \& Kamei, 2004). The H3R antagonists DL77 showed anticonvulsant effect in MES-induced seizure, and the anticonvulsant effect of DL77 in MES model was reversed by H1R antagonist pyrilamine (Sadek, Saad, Subramanian, Shafiullah, Łażewska \& Kieć-Kononowiczc, 2016), suggesting the action is H1R-dependent. Besides, in the rhythmic vestibular stimulation epilepsy like mice, H3R antagonist thioperamide decreased the induction of seizure (Yawata, Tanaka, Nakagawa, Watanabe, Murashima \& Nakano, 2004). Furthermore, different degree of antiepileptic and anticonvulsant effects of novel non-imidazole H3R antagonist ligands have been found in PTZ, STR and MES-induced seizure model (Alachkar et al., 2018a; Alachkar et al., 2018b; Bastaki, Abdulrazzaq, Shafiullah, Wiecek, Kieć-Kononowicz \& Sadek, 2018; Sadek et al., 2014a; Sadek et al., 2016; Sadek, Saad, Schwed, Weizel, Walter \& Stark, 2016; Song, Yan, Zhang, Guo, Zhou \& Deng, 2020). H3R antagonist, ABT-239, delayed onset of seizure and reduced behavioral seizures and restored altered expression of Bax, cleaved caspase-3, phospho-Akt (Ser473) and CREB in KA mice (Bhowmik, Saini \& Vohora, 2014). Another H3R antagonist E177, also shows protective effect in pilocarpine induced statue epilepticus rat indicating by increasing the survival rate and prolonging latency to the first seizure, and this effect was blocked by H3R agonist R- $(\alpha)$-methylhistamine and H2R antagonist zolantidine, but not H1R antagonist pyrilamine (Alachkar et al., 2019). Moreover, the H3R naphthalene derivatives 
compound 13 also shows protective effect of seizure in PTZ and 6-Hz stimulation model (Lażewska et al., 2018). It needs to note that the H3R naphthalene derivatives compound 13 was accepted by the National Institute of Neurological Disorders and Stroke/National Institutes of Health (NINDS/NIH; Rockville, MD, USA) started an Anticonvulsant Screening Program (ASP) (Eażewska et al., 2018). This compound 13 shows the possibility to enter clinical trials and be marketed as pitolisant. Betahistine, an H1R agonist/H3R antagonist shows good protective effect indicating by preventing generalized tonic-clonic seizures induction and diminishing forelimb clonic seizures intensity in PTZ treated mice (Yazdi, Doostmohammadi, Pourhossein Majarshin \& Beheshti, 2020). Betahistine reduced ADD without changing the seizure ranks in amygdaloid kindling rats (Yoshida, Noguchi \& Tsuru, 2000).

The PTZ induced epileptic seizure model usually accompanied by learning and memory deficits, which can be rescued by L-histidine (Chen, Ren, Zhang \& Hu, 2012; Zhang, Ma \& Li, 2006), and H3R antagonist, thioperamide, JNJ-5207852, and E177 (Alachkar et al., 2020; Jia et al., 2006; Zhang, Chen, Chen, Hu \& Ding, 2013), and this effect of L-histidine might through H2R but not H1R (Zhang, Chen, Chen, He \& Hu, 2017). Histidine promotes the anticonvulsant efficacy of carbamazepine and ameliorates the memory deficits induced by chronic transuricular kindled seizure (Li et al., 2005; Li, Liu, Zhu, Zhou \& Chen, 2006).

Although, in most cases, H3R antagonists/inverse agonists show good anti-seizure effects in different epilepsy models. The negative outcome also has been found in non-imidazole H3R antagonists/inverse agonists containing triazole moiety in PTZ mice (Song, Yan, Zhang, Guo, Zhou \& Deng, 2020), and the non-imidazole H3R antagonists DL77 in STR rat (Sadek, Saad, Subramanian, Shafiullah, Łażewska \& Kieć-Kononowiczc, 2016). The H3R antagonist, thioperamide shows no effect on seizure ranks and ADD in amygdaloid kindling rats (Yoshida, Noguchi \& Tsuru, 2000). Whether histamine-independent signaling is involved in the antiseizure effect of H3R antagonists/inverse agonists is still unknown.

4.3 The genetic and other therapeutics effects of targeting histamine and histamine receptors on epilepsy in animal model

Since histamine and its precursor L-histidine, as well as most H3R antagonists obtain positive outcomes. As pharmacological modulation is often associated with non-specific effect, genetically intervention can address the precise role of central histaminergic signaling epilepsy more specifically.

The H1R-KO mice showed more severe seizures with correlation of neuronal damage in the thalamus and RGC in P9 immature mice (Kukko-Lukjanov et al., 2010). Those authors then described the age-dependent susceptibility of H1R-KO mice to seizure-induced by KA administration: P14 H1R-KO mice showed no changes; P21 KO mice decreased survival rate with more severe seizures and enhanced neuronal damage in various brain regions; P60 KO mice increased the neuronal damage without changing the seizure severity (Kukko-Lukjanov et al., 2012). In the HDC-KO mice, the hyperthermia-induced febrile seizure was more severe that wide type (WT) mice (Dai et al., 2015). These findings indicate that deletion of H1R and HDC increases the susceptibility of epilepsy.

Based on the above researches results, it can be basically concluded that the central histaminergic signaling participates in epilepsy. Most importantly, the H3R antagonist shows powerful anti-epileptic and anticonvulsant effects in many epileptic animal models. The protective effect of H3R antagonist works mainly through H1R. However controversial opinion still exists (Alachkar et al., 2019; Sadek, Saad, Subramanian, Shafiullah, Łażewska \& Kieć-Kononowiczc, 2016). What's more, the action of H1R antagonists in seizure animal model also not consistent. The incomplete understanding of these issues needs further studies to investigate.

\section{Perspectives and Conclusion}

Current evidence from available clinical and preclinical studies supports that histamine and histamine receptor involves in the pathogenesis of epilepsy. There are still numerous unsolved issues left behind.

5.1 What is the role of other histamine receptors in epilepsy? 
H1R and H3R expression have been merely detected in one type of epilepsy animal model. The changes of histamine receptors need systemic animal researches and autopsy studies to elucidate further, especially H2R and H4R. In addition, H1R, H2R and H3R antagonists have been investigated in many epilepsy animal model, however, the report of H4R in epilepsy is still missing. Even the H4R shows the potential in regulating neuronal excitability (Desmadryl et al., 2012). Investigations should be implemented to detect the distribution and expression of H4R in epilepsy animal, and applying H4R agonists and antagonists to epilepsy intervention. What' more, some studies found that action of H3R ligands relies on H1R or H2R, the specific histamine receptor KO mice are available to ensure the action of H3R antagonist through H1R or $\mathrm{H} 2 \mathrm{R}$.

Even the H3R antagonists receive a lot of attention upon its desirable anti-epileptic and anticonvulsant effects, the action manner of H3R antagonists is not fully understood. As H3R is identified as either autoreceptor or heteroreceptor, it may be very complex about how it regulates neural excitability and thus related in epilepsy. For example, it is still largely unknown whether histamine-independent signaling is involved in the anti-seizure effect of H3R antagonists/inverse agonists. In the cerebral ischemia/reperfusion injury, the H3R antagonists protect against the ischemia injury in a histamine independent manner by directly recruiting binding of CLIC4 with H3R (Yan et al., 2014). Whether the action of H3R antagonist is the same in epilepsy that is unclear. HDC inhibitors and HDC-KO animal are regarded as a good choice to answer this question.

5.2 What is the neuronal circuit basis of histaminergic system in epilepsy?

According to the electrographic feature, the epileptic seizure is usually composed of a beginning, a middle and an end, which is associated with seizure initiation, propagation, and termination (Bertram, 2013). There are different neural networks involved in each stage (Wang \& Chen, 2019). It is well known that the histaminergic fibers widely project in the brain. Histaminergic system participates in particular one period or the whole process is obscured. Given an example, the nucleus of solitary tract shows an promising neuroprotective role in patients with poorly controlled epilepsy (Cakmak, 2006). It has reported that the histaminergic input from TMN to the solitary tract nucleus participating in arterial pressure regulation (Yamanaka, Gouraud, Takagishi, Kohsaka, Maeda \& Waki, 2017). Whether the TMN-solitary tract histaminergic projection regulates epilepsy needs validate further.

Interestingly, although histamine and several histamine receptors receive positive response in epileptic seizure, DBS directly on TMN showed a dominant protection accompanying with a prominent increase of histamine release in the frontal cortex after TMN stimulation in PTZ rats (Nishida, Huang, Mikuni, Miura, Urade \& Hashimoto, 2007). However, LFS of the TMN had no appreciable effects in PTZ model (Wu et al., 2008). LFS of the TMN accelerated seizure stage and increased the mean afterdischarge duration (ADD) during acquisition but had no anticonvulsive effect in fully kindled, HFS and bilateral lesions of TMN exacerbated the seizure progression in the amygdaloid kindling (Wu et al., 2008). These finding supports that DBS on TMN is not a good therapeutic approach to control seizure. Advanced technologies, such as novel optogenetics (Kim, Adhikari \& Deisseroth, 2017), in combination with novel viral tracing system (Nectow \& Nestler, 2020; Xu et al., 2020), provide high temporal and spatial specificity to reveal the circuit basis of histaminergic system in epilepsy.

5.3 What is the cellular and molecular mechanism of histaminergic system in epilepsy?

The imbalance of excitatory glutamatergic and inhibitory GABAergic neurons is considered as the classical theory for epilepsy. The action of histamine is localized in histaminergic neurons or innervating to glutamatergic or GABAergic neurons which is not fully understood. The well development of transgenic mice, such as HDC-Cre, CamKII $\alpha$-Cre, and Vgat-Cre are available to neuronal specific modulation with the help of optogenetic. H3R acts as heteroreceptor which regulates other neurotransmitters synthesis and release. In the cultured cortical neurons, the H3R antagonist clobenopropit effectively reduced the NMDAinduced neuronal toxicity by increasing GABA releases through cAMP/PKA signaling pathway (Dai et al., 2007). Whether other neurotransmitters, such as glutamate, GABA, acetylcholine and 5-HT participating in the action of H3R needs to identify further. Voltage-gated ion channels including $\mathrm{Na}^{+}, \mathrm{Ca}^{2+}$ and $\mathrm{K}^{+}$ 
channels, contribute to the generation of seizure discharges (Catterall, 2014; van Loo et al., 2019; Wei et al., 2017; Yuan \& Isom, 2014). Whether histamine or its receptor regulate voltage-gated ion channels activity in epilepsy needs further evaluation. Since cellular single RNA sequencing with high efficiency (Lein, Borm \& Linnarsson, 2017), that provides a convenient way to investigate the molecular mechanism.

In conclusion, plenty of evidence suggested the histamine and its receptor are involved in epilepsy. The discovery of the central histaminergic system broadens the AED development aspects, especially for H3R antagonists. Nevertheless, there are many questions unsolved. A precise understanding of the role of the central histaminergic system in epilepsy at molecular, cellular, or even neural circuit level is encouraged to clinical transformation in epilepsy therapeutics.

\section{Acknowledgments}

This work was supported by grants from the National Natural Science Foundation of China (81630098, 82022071 and 81821091).

\section{Conflict of interests}

The authors declare that there are no conflicts of interest.

\section{References}

Ago J, Ishikawa T, Matsumoto N, Ashequr Rahman M, \& Kamei C (2006). Mechanism of imipramineinduced seizures in amygdala-kindled rats. Epilepsy research 72: 1-9.

Alachkar A, Azimullah S, Lotfy M, Adeghate E, Ojha SK, Beiram R, et al. (2020). Antagonism of Histamine H3 receptors Alleviates Pentylenetetrazole-Induced Kindling and Associated Memory Deficits by Mitigating Oxidative Stress, Central Neurotransmitters, and c-Fos Protein Expression in Rats. Molecules (Basel, Switzerland) 25 .

Alachkar A, Azimullah S, Ojha SK, Beiram R, Łażewska D, Kieć-Kononowicz K, et al. (2019). The Neuroprotective Effects of Histamine H3 Receptor Antagonist E177 on Pilocarpine-Induced Status Epilepticus in Rats. Molecules (Basel, Switzerland) 24.

Alachkar A, Latacz G, Siwek A, Lubelska A, Honkisz E, Gryboś A, et al. (2018a). Anticonvulsant evaluation of novel non-imidazole histamine H3R antagonists in different convulsion models in rats. Pharmacology, biochemistry, and behavior 170: 14-24.

Alachkar A, Łażewska D, Latacz G, Frank A, Siwek A, Lubelska A, et al. (2018b). Studies on Anticonvulsant Effects of Novel Histamine H3R Antagonists in Electrically and Chemically Induced Seizures in Rats. International journal of molecular sciences 19.

Arrang JM, Garbarg M, \& Schwartz JC (1983). Auto-inhibition of brain histamine release mediated by a novel class (H3) of histamine receptor. Nature 302: 832-837.

Bañuelos-Cabrera I, Cuéllar-Herrera M, Velasco AL, Velasco F, Alonso-Vanegas M, Carmona F, et al. (2016). Pharmacoresistant temporal lobe epilepsy modifies histamine turnover and $\mathrm{H} 3$ receptor function in the human hippocampus and temporal neocortex. Epilepsia 57: e76-80.

Bastaki SM, Abdulrazzaq YM, Shafiullah M, Wiecek M, Kieć-Kononowicz K, \& Sadek B (2018). Anticonvulsant and reproductive toxicological studies of the imidazole-based histamine H3R antagonist 2-18 in mice. Drug design, development and therapy 12: 179-194.

Bertram EH (2013). Neuronal circuits in epilepsy: do they matter? Exp Neurol 244: 67-74.

Bhowmik M, Saini N, \& Vohora D (2014). Histamine H3 receptor antagonism by ABT-239 attenuates kainic acid induced excitotoxicity in mice. Brain research 1581: 129-140.

Cakmak YO (2006). Epilepsy, electroacupuncture and the nucleus of the solitary tract. Acupuncture in medicine : journal of the British Medical Acupuncture Society 24: 164-168. 
Carrasco MA, Jaimovich E, Kemmerling U, \& Hidalgo C (2004). Signal transduction and gene expression regulated by calcium release from internal stores in excitable cells. Biological research 37:701-712.

Catterall WA (2014). Sodium channels, inherited epilepsy, and antiepileptic drugs. Annual review of pharmacology and toxicology 54: 317-338.

Cerminara C, El-Malhany N, Roberto D, Lo Castro A, \& Curatolo P (2013). Seizures induced by desloratadine, a second-generation antihistamine: clinical observations. Neuropediatrics 44: 222-224.

Chen GF, Ren GL, Zhang LS, \& Hu XY (2012). [Effects of Wuling mycelia on pentylenetetrazole-induced epilepsy in rats]. Zhejiang da xue xue bao Yi xue ban $=$ Journal of Zhejiang University Medical sciences 41: 647-652.

Chen K, Wang JJ, Yung WH, Chan YS, \& Chow BK (2005). Excitatory effect of histamine on neuronal activity of rat globus pallidus by activation of $\mathrm{H} 2$ receptors in vitro. Neuroscience research 53: 288-297.

Chen Z, Li WD, Zhu LJ, Shen YJ, \& Wei EQ (2002). Effects of histidine, a precursor of histamine, on pentylenetetrazole-induced seizures in rats. Acta pharmacologica Sinica 23: 361-366.

Chen Z, Sakurai E, Hu W, Jin C, Kiso Y, Kato M, et al. (2004). Pharmacological effects of carcinine on histaminergic neurons in the brain. British journal of pharmacology 143: 573-580.

Cilz NI, \& Lei S (2017). Histamine facilitates GABAergic transmission in the rat entorhinal cortex: Roles of $\mathrm{H}(1)$ and $\mathrm{H}(2)$ receptors, $\mathrm{Na}(+)$-permeable cation channels, and inward rectifier $\mathrm{K}(+)$ channels. Hippocampus 27: 613-631.

Cogé F, Guénin SP, Rique H, Boutin JA, \& Galizzi JP (2001). Structure and expression of the human histamine H4-receptor gene. Biochemical and biophysical research communications 284: 301-309.

Collart Dutilleul P, Ryvlin P, Kahane P, Vercueil L, Semah F, Biraben A, et al. (2016). Exploratory Phase II Trial to Evaluate the Safety and the Antiepileptic Effect of Pitolisant (BF2.649) in Refractory Partial Seizures, Given as Adjunctive Treatment During 3 Months. Clinical neuropharmacology 39: 188-193.

Connelly WM, Shenton FC, Lethbridge N, Leurs R, Waldvogel HJ, Faull RL, et al. (2009). The histamine $\mathrm{H} 4$ receptor is functionally expressed on neurons in the mammalian CNS. British journal of pharmacology 157: 55-63.

Dai H, Fu Q, Shen Y, Hu W, Zhang Z, Timmerman H, et al. (2007). The histamine H3 receptor antagonist clobenpropit enhances GABA release to protect against NMDA-induced excitotoxicity through the cAMP/protein kinase A pathway in cultured cortical neurons. European journal of pharmacology 563: 117123.

Dai YJ, Wu DC, Feng B, Hou WW, Xu CL, Ohtsu H, et al. (2015). Protective effect of carnosine on febrile seizures in immature mice. Neuroscience letters 588: 95-100.

De Luca R, Suvorava T, Yang D, Baumgärtel W, Kojda G, Haas HL, et al. (2016). Identification of histaminergic neurons through histamine 3 receptor-mediated autoinhibition. Neuropharmacology 106:102-115.

Desmadryl G, Gaboyard-Niay S, Brugeaud A, Travo C, Broussy A, Saleur A, et al. (2012). Histamine H4 receptor antagonists as potent modulators of mammalian vestibular primary neuron excitability. British journal of pharmacology 167: 905-916.

Ellenbroek BA, \& Ghiabi B (2014). The other side of the histamine H3 receptor. Trends in neurosciences 37: 191-199.

Engel J, Jr. (2018). The current place of epilepsy surgery. Current opinion in neurology 31: 192-197.

Enrique AV, Di Ianni ME, Goicoechea S, Lazarowski A, Valle-Dorado MG, Costa JJL, et al. (2019). New anticonvulsant candidates prevent P-glycoprotein (P-gp) overexpression in a pharmacoresistant seizure model in mice. Epilepsy \& behavior : E\&B: 106451. 
Erickson JD, Schafer MK, Bonner TI, Eiden LE, \& Weihe E (1996). Distinct pharmacological properties and distribution in neurons and endocrine cells of two isoforms of the human vesicular monoamine transporter. Proceedings of the National Academy of Sciences of the United States of America 93: 5166-5171.

Feng HJ, \& Faingold CL (2000). Modulation of audiogenic seizures by histamine and adenosine receptors in the inferior colliculus. Experimental neurology 163: 264-270.

Feng HJ, Naritoku DK, Randall ME, \& Faingold CL (2001). Modulation of audiogenically kindled seizures by gamma-aminobutyric acid-related mechanisms in the amygdala. Experimental neurology 172:477-481.

Fernandes CEM, \& Serafim KR (2019). Systemic injection of an H4 receptor agonist induces a decrease in CREB and pCREB levels in the cerebellar vermis and prefrontal cortex in mice. 52: e8334.

Fernandes CEM, Serafim KR, Gianlorenco ACL, \& Mattioli R (2017). Intra-vermis H4 receptor agonist impairs performance in anxiety- and fear-mediated models. Brain research bulletin 135: 179-184.

Fujii Y, Tanaka T, Harada C, Hirai T, \& Kamei C (2003). Epileptogenic activity induced by histamine H(1) antagonists in amygdala-kindled rats. Brain research 991: 258-261.

Gholipoor P, Saboory E, Roshan-Milani S, \& Fereidoni J (2013). Effect of hyperthermia on histamine blood level and convulsive behavior in infant rats. Epilepsy \& behavior : E\&B 29: 269-274.

Giovannini MG, Efoudebe M, Passani MB, Baldi E, Bucherelli C, Giachi F, et al. (2003). Improvement in fear memory by histamine-elicited ERK2 activation in hippocampal CA3 cells. The Journal of neuroscience : the official journal of the Society for Neuroscience 23: 9016-9023.

Haas HL, Sergeeva OA, \& Selbach O (2008). Histamine in the nervous system. Physiological reviews 88: $1183-1241$.

Harada C, Fujii Y, Hirai T, Shinomiya K, \& Kamei C (2004). Inhibitory effect of iodophenpropit, a selective histamine H3 antagonist, on amygdaloid kindled seizures. Brain research bulletin 63:143-146.

Harada C, Hirai T, Fujii Y, Harusawa S, Kurihara T, \& Kamei C (2004). Intracerebroventricular administration of histamine $\mathrm{H} 3$ receptor antagonists decreases seizures in rat models of epilepsia. Methods and findings in experimental and clinical pharmacology 26: 263-270.

Harwell V, \& Fasinu PS (2020). Pitolisant and Other Histamine-3 Receptor Antagonists-An Update on Therapeutic Potentials and Clinical Prospects. Medicines (Basel, Switzerland) 7.

Ishikawa T, Takechi K, Rahman A, Ago J, Matsumoto N, Murakami A, et al. (2007). Influences of histamine H1 receptor antagonists on maximal electroshock seizure in infant rats. Biological \& pharmaceutical bulletin 30: 477-480.

Jahan K, Pillai KK, \& Vohora D (2017). Parachlorophenylalanine-induced 5-HT depletion alters behavioral and brain neurotransmitters levels in 6-Hz psychomotor seizure model in mice. Fundamental \& clinical pharmacology 31: 403-410.

Jang IS, Rhee JS, Watanabe T, Akaike N, \& Akaike N (2001). Histaminergic modulation of GABAergic transmission in rat ventromedial hypothalamic neurones. The Journal of physiology 534: 791-803.

Ji MJ, Zhang XY, Peng XC, Zhang YX, Chen Z, Yu L, et al. (2018). Histamine Excites Rat GABAergic Ventral Pallidum Neurons via Co-activation of H1 and H2 Receptors. Neuroscience bulletin 34:1029-1036.

Jia F, Kato M, Dai H, Xu A, Okuda T, Sakurai E, et al. (2006). Effects of histamine H(3) antagonists and donepezil on learning and mnemonic deficits induced by pentylenetetrazol kindling in weanling mice. Neuropharmacology 50: 404-411.

Jin C, Lintunen M, \& Panula $\mathrm{P}$ (2005). Histamine $\mathrm{H}(1)$ and $\mathrm{H}(3)$ receptors in the rat thalamus and their modulation after systemic kainic acid administration. Experimental neurology 194: 43-56. 
Jin CL, Zhuge ZB, Wu DC, Zhu YY, Wang S, Luo JH, et al. (2007). Lesion of the tuberomammillary nucleus E2-region attenuates postictal seizure protection in rats. Epilepsy research 73: 250-258.

Kaeberle J (2018). Epilepsy Disorders and Treatment Modalities. NASN school nurse (Print) 33: 342-344.

Kamei C, Ishizawa K, Kakinoki H, \& Fukunaga M (1998). Histaminergic mechanisms in amygdaloid-kindled seizures in rats. Epilepsy research 30: 187-194.

Karlstedt K, Sallmén T, Eriksson KS, Lintunen M, Couraud PO, Joó F, et al. (1999). Lack of histamine synthesis and down-regulation of $\mathrm{H} 1$ and $\mathrm{H} 2$ receptor mRNA levels by dexamethasone in cerebral endothelial cells. Journal of cerebral blood flow and metabolism : official journal of the International Society of Cerebral Blood Flow and Metabolism 19: 321-330.

Kasteleijn-Nolst Trenité D, Parain D, Genton P, Masnou P, Schwartz JC, \& Hirsch E (2013). Efficacy of the histamine 3 receptor (H3R) antagonist pitolisant (formerly known as tiprolisant; BF2.649) in epilepsy: dose-dependent effects in the human photosensitivity model. Epilepsy \& behavior : E\&B 28: 66-70.

Katoh Y, Niimi M, Yamamoto Y, Kawamura T, Morimoto-Ishizuka T, Sawada M, et al. (2001). Histamine production by cultured microglial cells of the mouse. Neuroscience letters 305: 181-184.

Khateb A, Fort P, Pegna A, Jones BE, \& Mühlethaler M (1995). Cholinergic nucleus basalis neurons are excited by histamine in vitro. Neuroscience 69: 495-506.

Kim CK, Adhikari A, \& Deisseroth K (2017). Integration of optogenetics with complementary methodologies in systems neuroscience. Nature reviews Neuroscience 18: 222-235.

Korotkova TM, Haas HL, \& Brown RE (2002). Histamine excites GABAergic cells in the rat substantia nigra and ventral tegmental area in vitro. Neuroscience letters 320: 133-136.

Kukko-Lukjanov TK, Grönman M, Lintunen M, Laurén HB, Michelsen KA, Panula P, et al. (2012). Histamine 1 receptor knock out mice show age-dependent susceptibility to status epilepticus and consequent neuronal damage. Epilepsy research 100: 80-92.

Kukko-Lukjanov TK, Lintunen M, Jalava N, Laurén HB, Lopez-Picon FR, Michelsen KA, et al. (2010). Involvement of histamine 1 receptor in seizure susceptibility and neuroprotection in immature mice. Epilepsy research 90: 8-15.

Kwiatkowski H (1943). Histamine in nervous tissue. The Journal of physiology 102: 32-41.

Löscher W (2011). Critical review of current animal models of seizures and epilepsy used in the discovery and development of new antiepileptic drugs. Seizure 20: 359-368.

Löscher W, Klitgaard H, Twyman RE, \& Schmidt D (2013). New avenues for anti-epileptic drug discovery and development. Nature reviews Drug discovery 12: 757-776.

Labarinas S, Meulmester K, Greene S, Thomas J, Virk M, \& Erkonen G (2018). Extracorporeal Cardiopulmonary Resuscitation After Diphenhydramine Ingestion. Journal of medical toxicology : official journal of the American College of Medical Toxicology 14:253-256.

Łażewska D, Kaleta M, Hagenow S, Mogilski S, Latacz G, Karcz T, et al. (2018). Novel naphthyloxy derivatives - Potent histamine H(3) receptor ligands. Synthesis and pharmacological evaluation. Bioorganic \& medicinal chemistry 26: 2573-2585.

Lein E, Borm LE, \& Linnarsson S (2017). The promise of spatial transcriptomics for neuroscience in the era of molecular cell typing. Science 358: 64-69.

Leurs R, Traiffort E, Arrang JM, Tardivel-Lacombe J, Ruat M, \& Schwartz JC (1994). Guinea pig histamine H1 receptor. II. Stable expression in Chinese hamster ovary cells reveals the interaction with three major signal transduction pathways. Journal of neurochemistry 62:519-527. 
Li B, Zhang XY, Yang AH, Peng XC, Chen ZP, Zhou JY, et al.(2016). Histamine Increases Neuronal Excitability and Sensitivity of the Lateral Vestibular Nucleus and Promotes Motor Behaviors via HCN Channel Coupled to H2 Receptor. Frontiers in cellular neuroscience 10:300.

Li D, Carozza RB, Shatos MA, Hodges RR, \& Dartt DA (2012). Effect of histamine on Ca(2+)-dependent signaling pathways in rat conjunctival goblet cells. Investigative ophthalmology \& visual science 53:69286938 .

Li Q, Jin CL, Xu LS, Zhu-Ge ZB, Yang LX, Liu LY, et al. (2005). Histidine enhances carbamazepine action against seizures and improves spatial memory deficits induced by chronic transauricular kindling in rats. Acta pharmacologica Sinica 26: 1297-1302.

Li Q, Liu LY, Zhu YY, Zhou WX, \& Chen Z (2006). [Effect of chronic transauricular kindled seizures on passive-avoidance test memory retention in rats]. Zhejiang da xue xue bao Yi xue ban = Journal of Zhejiang University Medical sciences 35: 419-423.

Lintunen M, Sallmen T, Karlstedt K, \& Panula P (2005). Transient changes in the limbic histaminergic system after systemic kainic acid-induced seizures. Neurobiology of disease 20: 155-169.

Liu B, Zhang X, Wang C, Zhang G, \& Zhang H (2008). Antihistamine mepyramine directly inhibits KCNQ/M channel and depolarizes rat superior cervical ganglion neurons. Neuropharmacology 54: 629639.

Lovenberg TW, Roland BL, Wilson SJ, Jiang X, Pyati J, Huvar A, et al. (1999). Cloning and functional expression of the human histamine H3 receptor. Molecular pharmacology 55: 1101-1107.

Lundius EG, Sanchez-Alavez M, Ghochani Y, Klaus J, \& Tabarean IV (2010). Histamine influences body temperature by acting at $\mathrm{H} 1$ and $\mathrm{H} 3$ receptors on distinct populations of preoptic neurons. The Journal of neuroscience : the official journal of the Society for Neuroscience 30: 4369-4381.

Manz KM, Becker JC, Grueter CA, \& Grueter BA (2020). Histamine H(3) Receptor Function Biases Excitatory Gain in the Nucleus Accumbens. Biological psychiatry.

Meller S, Brandt C, Theilmann W, Klein J, \& Löscher W (2019). Commonalities and differences in extracellular levels of hippocampal acetylcholine and amino acid neurotransmitters during status epilepticus and subsequent epileptogenesis in two rat models of temporal lobe epilepsy. Brain research 1712: 109-123.

Midzyanovskaya IS, \& Tuomisto L (2003). Increased density of H1 histamine receptors in brain regions of rats with absence epilepsy. Inflammation research : official journal of the European Histamine Research Society [et al] 52 Suppl 1: S29-30.

Nectow AR, \& Nestler EJ (2020). Viral tools for neuroscience. Nature reviews Neuroscience 21: 669-681.

Nishida N, Huang ZL, Mikuni N, Miura Y, Urade Y, \& Hashimoto N (2007). Deep brain stimulation of the posterior hypothalamus activates the histaminergic system to exert antiepileptic effect in rat pentylenetetrazol model. Experimental neurology 205: 132-144.

Onodera K, Tuomisto L, Tacke U, \& Airaksinen M (1992). Strain differences in regional brain histamine levels between genetically epilepsy-prone and resistant rats. Methods and findings in experimental and clinical pharmacology 14: 13-16.

Peng SY, Zhuang QX, He YC, Zhu JN, \& Wang JJ (2013). Histamine excites neurons of the inferior vestibular nucleus in rats by activation of $\mathrm{H} 1$ and $\mathrm{H} 2$ receptors. Neuroscience letters 541: 87-92.

Potschka H (2012). Animal models of drug-resistant epilepsy. Epileptic disorders : international epilepsy journal with videotape 14:226-234.

Qin YT, Ma SH, Zhuang QX, Qiu YH, Li B, Peng YP, et al. (2011). Histamine evokes excitatory response of neurons in the cerebellar dentate nucleus via H2 receptors. Neuroscience letters 502:133-137. 
Raible DG, Lenahan T, Fayvilevich Y, Kosinski R, \& Schulman ES (1994). Pharmacologic characterization of a novel histamine receptor on human eosinophils. American journal of respiratory and critical care medicine 149: 1506-1511.

Sáez ME, González-Pérez A, Gaist D, Johansson S, Nagy P, \& García Rodríguez LA (2016). Risk of seizure associated with use of acid-suppressive drugs: An observational cohort study. Epilepsy \& behavior : E\&B 62: $72-80$.

Sadek B, Kuder K, Subramanian D, Shafiullah M, Stark H, Lażewska D, et al. (2014a). Anticonvulsive effect of nonimidazole histamine H3 receptor antagonists. Behavioural pharmacology 25:245-252.

Sadek B, Saad A, Latacz G, Kuder K, Olejarz A, Karcz T, et al.(2016). Non-imidazole-based histamine H3 receptor antagonists with anticonvulsant activity in different seizure models in male adult rats. Drug design, development and therapy 10: 3879-3898.

Sadek B, Saad A, Sadeq A, Jalal F, \& Stark H (2016). Histamine H3 receptor as a potential target for cognitive symptoms in neuropsychiatric diseases. Behavioural brain research 312:415-430.

Sadek B, Saad A, Schwed JS, Weizel L, Walter M, \& Stark H (2016). Anticonvulsant effects of isomeric nonimidazole histamine $\mathrm{H}(3)$ receptor antagonists. Drug design, development and therapy 10:3633-3651.

Sadek B, Saad A, Subramanian D, Shafiullah M, Łażewska D, \& Kieć-Kononowiczc K (2016). Anticonvulsant and procognitive properties of the non-imidazole histamine $\mathrm{H} 3$ receptor antagonist DL77 in male adult rats. Neuropharmacology 106: 46-55.

Sadek B, Schwed JS, Subramanian D, Weizel L, Walter M, Adem A, et al. (2014b). Non-imidazole histamine H3 receptor ligands incorporating antiepileptic moieties. European journal of medicinal chemistry 77: 269279 .

Sadek B, Shehab S, Wiecek M, Subramanian D, Shafiullah M, Kieć-Kononowicz K, et al. (2013). Anticonvulsant properties of histamine $\mathrm{H} 3$ receptor ligands belonging to N-substituted carbamates of imidazopropanol. Bioorganic \& medicinal chemistry letters 23:4886-4891.

Samotaeva IS, Birioukova LM, Midzyanovskaya IS, Kuznetsova GD, Bazyan AS, \& Tuomisto L (2012). Metoprine induced behavioral modifications and brain regional histamine increase in WAG/Rij and Wistar rats. Epilepsy research 101: 148-156.

Sanna MD, Borgonetti V, Masini E, \& Galeotti N (2020). Histamine H(4) receptor stimulation in the locus coeruleus attenuates neuropathic pain by promoting the coeruleospinal noradrenergic inhibitory pathway. European journal of pharmacology 868: 172859 .

Sanna MD, Ghelardini C, Thurmond RL, Masini E, \& Galeotti N (2017). Behavioural phenotype of histamine $\mathrm{H}(4)$ receptor knockout mice: Focus on central neuronal functions. Neuropharmacology 114: 48-57.

Sanna MD, Mello T, Masini E, \& Galeotti N (2018). Activation of ERK/CREB pathway in noradrenergic neurons contributes to hypernociceptive phenotype in $\mathrm{H} 4$ receptor knockout mice after nerve injury. Neuropharmacology 128: 340-350.

Schaper F, Plantinga BR, Colon AJ, Wagner GL, Boon P, Blom N, et al. (2020). Deep Brain Stimulation in Epilepsy: A Role for Modulation of the Mammillothalamic Tract in Seizure Control? Neurosurgery 87: 602-610.

Schneider EH, Neumann D, \& Seifert R (2014). Modulation of behavior by the histaminergic system: lessons from H(1)R-and H(2)R-deficient mice. Neuroscience and biobehavioral reviews 42: 252-266.

Schneider EH, \& Seifert R (2016). The histamine H4-receptor and the central and peripheral nervous system: A critical analysis of the literature. Neuropharmacology 106: 116-128. 
Seeley N, \& Sturman G (2001). Effect of amthamine, a histamine H2-agonist, in two mouse chemical-induced seizure models. Inflammation research : official journal of the European Histamine Research Society [et al] 50 Suppl 2: S82-83.

Selbach O, Brown RE, \& Haas HL (1997). Long-term increase of hippocampal excitability by histamine and cyclic AMP. Neuropharmacology 36: 1539-1548.

Singh E, Pillai KK, \& Mehndiratta M (2014). Characterization of a lamotrigine-resistant kindled model of epilepsy in mice: evaluation of drug resistance mechanisms. Basic \& clinical pharmacology \& toxicology 115: $373-378$.

Song M, Yan R, Zhang Y, Guo D, Zhou N, \& Deng X (2020). Design, synthesis, and anticonvulsant effects evaluation of nonimidazole histamine $\mathrm{H}(3)$ receptor antagonists/inverse agonists containing triazole moiety. Journal of enzyme inhibition and medicinal chemistry 35: 1310-1321.

Stevens DR, Eriksson KS, Brown RE, \& Haas HL (2001). The mechanism of spontaneous firing in histamine neurons. Behavioural brain research 124: 105-112.

Sturman G, Freeman P, \& Quinn L (2001). Histamine H1-antagonists potentiate seizures in the EL (epilepsylike) mouse model of temporal lobe epilepsy. Inflammation research : official journal of the European Histamine Research Society [et al] 50 Suppl 2: S80-81.

Sugitate R, Okubo Y, Nariai H, \& Matsui A (2020). The effects of antihistamine on the duration of the febrile seizure: A single center study with a systematic review and meta-analysis. Brain \& development 42 : 103-112.

Swiader M, Wielosz M, \& Czuczwar SJ (2004). Influence of antazoline and ketotifen on the anticonvulsant activity of conventional antiepileptics against maximal electroshock in mice. European neuropsychopharmacology : the journal of the European College of Neuropsychopharmacology 14: 307-318.

Swiader MJ, Porebiak J, Swiader K, Wielosz M, \& Czuczwar SJ (2006). Influence of cimetidine on the anticonvulsant activity of conventional antiepileptic drugs against pentetrazole-induced seizures in mice. Pharmacological reports : PR 58: 131-134.

Szczepanska K, Kuder K, \& Kiec-Kononowicz K (2018). Histamine H3 Receptor Ligands in the Group of (Homo)piperazine Derivatives. Current medicinal chemistry 25: 1609-1626.

Szyndler J, Piechal A, Blecharz-Klin K, Skórzewska A, Maciejak P, Walkowiak J, et al. (2006). Effect of kindled seizures on rat behavior in water Morris maze test and amino acid concentrations in brain structures. Pharmacological reports : PR 58: 75-82.

Tian L, Wen YQ, Li HZ, Zuo CC, \& Wang JJ (2000). Histamine excites rat cerebellar Purkinje cells via H2 receptors in vitro. Neuroscience research 36: 61-66.

Toyota H, Dugovic C, Koehl M, Laposky AD, Weber C, Ngo K, et al.(2002). Behavioral characterization of mice lacking histamine $\mathrm{H}(3)$ receptors. Molecular pharmacology 62: 389-397.

Traiffort E, Vizuete ML, Tardivel-Lacombe J, Souil E, Schwartz JC, \& Ruat M (1995). The guinea pig histamine $\mathrm{H} 2$ receptor: gene cloning, tissue expression and chromosomal localization of its human counterpart. Biochemical and biophysical research communications 211:570-577.

Trinka E, Kwan P, Lee B, \& Dash A (2019). Epilepsy in Asia: Disease burden, management barriers, and challenges. Epilepsia 60 Suppl 1: 7-21.

Tuomisto L, Sturman G, Freeman P, \& Tarhanen J (2003). Brain histamine turnover and seizure behaviour in two mouse strains: preliminary findings. Inflammation research : official journal of the European Histamine Research Society [et al] 52 Suppl 1: S27-28. 
van Loo KMJ, Rummel CK, Pitsch J, Müller JA, Bikbaev AF, Martinez-Chavez E, et al. (2019). Calcium Channel Subunit $\alpha 2 \delta 4$ Is Regulated by Early Growth Response 1 and Facilitates Epileptogenesis. J Neurosci 39: 3175-3187.

Varaschin RK, Rosenberg MJ, Hamilton DA, \& Savage DD (2014). Differential effects of the histamine $\mathrm{H}(3)$ receptor agonist methimepip on dentate granule cell excitability, paired-pulse plasticity and long-term potentiation in prenatal alcohol-exposed rats. Alcoholism, clinical and experimental research 38: 1902-1911.

Vinogradova LV, Shatskova AB, \& Tuomisto L (2007). Histaminergic modulation of acoustically induced running behavior in rats. Brain research 1148: 198-204.

von Einsiedel RW, Roesch-Ely D, Diebold K, Sartor K, Mundt C, \& Bergemann N (2002). H(2)-histamine antagonist (famotidine) induced adverse CNS reactions with long-standing secondary mania and epileptic seizures. Pharmacopsychiatry 35: 152-154.

Wada Y, Shiraishi J, Nakamura M, \& Koshino Y (1996). Biphasic action of the histamine precursor Lhistidine in the rat kindling model of epilepsy. Neuroscience letters 204: 205-208.

Wang Y, \& Chen Z (2019). An update for epilepsy research and antiepileptic drug development: Toward precise circuit therapy. Pharmacology \& therapeutics 201: 77-93.

Wei F, Yan LM, Su T, He N, Lin ZJ, Wang J, et al. (2017). Ion Channel Genes and Epilepsy: Functional Alteration, Pathogenic Potential, and Mechanism of Epilepsy. Neuroscience bulletin 33: 455-477.

Wu DC, Zhu-Ge ZB, Yu CY, Fang Q, Wang S, Jin CL, et al. (2008). Low-frequency stimulation of the tuberomammillary nucleus facilitates electrical amygdaloid-kindling acquisition in Sprague-Dawley rats. Neurobiology of disease 32: 151-156.

Xu X, Holmes TC, Luo MH, Beier KT, Horwitz GD, Zhao F, et al.(2020). Viral Vectors for Neural Circuit Mapping and Recent Advances in Trans-synaptic Anterograde Tracers. Neuron 107: 1029-1047.

Yamada K, Takizawa F, Tamura T, \& Kanda T (2012). The effect of antihistamines on seizures induced by increasing-current electroshocks: ketotifen, but not olopatadine, promotes the seizures in infant rats. Biological \& pharmaceutical bulletin 35: 693-697.

Yamakami J, Sakurai E, Kuramasu A, Sakurai E, Yanai K, Watanabe T, et al. (2000). L-Histidine decarboxylase protein and activity in rat brain microvascular endothelial cells. Inflammation research : official journal of the European Histamine Research Society [et al] 49: 231-235.

Yamamoto Y, Lee D, Kim Y, Lee B, Seo C, Kawasaki H, et al.(2012). Raf kinase inhibitory protein is required for cerebellar long-term synaptic depression by mediating PKC-dependent MAPK activation. The Journal of neuroscience : the official journal of the Society for Neuroscience 32: 14254-14264.

Yamanaka K, Gouraud SS, Takagishi M, Kohsaka A, Maeda M, \& Waki H (2017). Evidence for a histaminergic input from the ventral tuberomammillary nucleus to the solitary tract nucleus involved in arterial pressure regulation. Physiological reports 5.

Yan H, Zhang X, Hu W, Ma J, Hou W, Zhang X, et al. (2014). Histamine H3 receptors aggravate cerebral ischaemic injury by histamine-independent mechanisms. Nat Commun 5: 3334-3334.

Yasuhara A, Ochi A, Harada Y, \& Kobayashi Y (1998). Infantile spasms associated with a histamine H1 antagonist. Neuropediatrics 29:320-321.

Yawata I, Tanaka K, Nakagawa Y, Watanabe Y, Murashima YL, \& Nakano K (2004). Role of histaminergic neurons in development of epileptic seizures in EL mice. Brain research Molecular brain research 132: 13-17.

Yazdi A, Doostmohammadi M, Pourhossein Majarshin F, \& Beheshti S (2020). Betahistine, prevents kindling, ameliorates the behavioral comorbidities and neurodegeneration induced by pentylenetetrazole. Epilepsy \& behavior : E\&B 105: 106956. 
Yokoyama H, Hirose M, Uematsu M, Haginoya K, Iinuma K, \& Kimura S (2012). Ketotifen overdose in infancy associated with development of epilepsy and mild mental retardation. Pediatrics international : official journal of the Japan Pediatric Society 54: 963.

Yokoyama H, Iinuma K, Yanai K, Watanabe T, Sakurai E, \& Onodera K (1993). Proconvulsant effect of ketotifen, a histamine H1 antagonist, confirmed by the use of d-chlorpheniramine with monitoring electroencephalography. Methods and findings in experimental and clinical pharmacology 15: 183-188.

Yokoyama H, Sato M, Iinuma K, Onodera K, \& Watanabe T (1996). Centrally acting histamine H1 antagonists promote the development of amygdala kindling in rats. Neuroscience letters 217: 194-196.

Yoshida M, Noguchi E, \& Tsuru N (2000). Lack of substantial effect of the H(3)-antagonist thioperamide and of the non-selective mixed $\mathrm{H}(3)$-antagonist/H(1)-agonist betahistine on amygdaloid kindled seizures. Epilepsy research 40: 141-145.

Yuan H, \& Silberstein SD (2018). Histamine and Migraine. Headache 58: 184-193.

Yuan Y, \& Isom LL (2014). SUMOylation of Neuronal K+ channels: a potential therapeutic pathway for epilepsy and SUDEP? Neuron 83: 996-998.

Zhang L, Chen G, Chen J, He X, \& Hu X (2017). [Mechanisms of histamine ameliorating memory impairment induced by pentylenetetrazole-kindling epilepsy in rats]. Zhejiang da xue xue bao Yi xue ban = Journal of Zhejiang University Medical sciences 46: 1-6.

Zhang L, Chen Z, Ren K, Leurs R, Chen J, Zhang W, et al. (2003). Effects of clobenpropit on pentylenetetrazole-kindled seizures in rats. European journal of pharmacology 482: 169-175.

Zhang LS, Chen JF, Chen GF, Hu XY, \& Ding MP (2013). Effects of thioperamide on seizure development and memory impairment induced by pentylenetetrazole-kindling epilepsy in rats. Chinese medical journal 126: $95-100$.

Zhang LS, Chen Z, Huang YW, Hu WW, Wei EQ, \& Yanai K (2003). Effects of endogenous histamine on seizure development of pentylenetetrazole-induced kindling in rats. Pharmacology 69:27-32.

Zhang LS, Ma YY, \& Li Q (2006). [Effects of endogenous histamine on memory impairment induced by pentylenetetrazole-kindled epilepsy in rats]. Zhejiang da xue xue bao Yi xue ban = Journal of Zhejiang University Medical sciences 35: 630-634.

Zhang LS, Shen HQ, Jin CL, Hu WW, Zhao MH, \& Chen Z (2004). [Mechanisms of the effect of brain histamine on chronic epilepsy induced by pentylenetetrazole]. Zhejiang da xue xue bao Yi xue ban = Journal of Zhejiang University Medical sciences 33: 201-204.

Zhang XY, Yu L, Zhuang QX, Peng SY, Zhu JN, \& Wang JJ (2013). Postsynaptic mechanisms underlying the excitatory action of histamine on medial vestibular nucleus neurons in rats. British journal of pharmacology 170: $156-169$.

Zhao H, Lin Y, Chen S, Li X, \& Huo H (2018). 5-HT3 Receptors: A Potential Therapeutic Target for Epilepsy. Current neuropharmacology 16: 29-36.

Zhou FW, Xu JJ, Zhao Y, LeDoux MS, \& Zhou FM (2006). Opposite functions of histamine H1 and H2 receptors and H3 receptor in substantia nigra pars reticulata. Journal of neurophysiology 96: 1581-1591.

Zhou J, Lee AW, Devidze N, Zhang Q, Kow LM, \& Pfaff DW (2007). Histamine-induced excitatory responses in mouse ventromedial hypothalamic neurons: ionic mechanisms and estrogenic regulation. Journal of neurophysiology 98: 3143-3152.

Zhou P, Homberg JR, Fang Q, Wang J, Li W, Meng X, et al. (2019). Histamine-4 receptor antagonist JNJ7777120 inhibits pro-inflammatory microglia and prevents the progression of Parkinson-like pathology and behaviour in a rat model. Brain, behavior, and immunity 76:61-73. 
Zhuang QX, Wu YH, Wu GY, Zhu JN, \& Wang JJ (2013). Histamine excites rat superior vestibular nuclear neurons via postsynaptic H1 and H2 receptors in vitro. Neuro-Signals 21: 174-183.

Zhuang QX, Xu HT, Lu XJ, Li B, Yung WH, Wang JJ, et al. (2018). Histamine Excites Striatal Dopamine D1 and D2 Receptor-Expressing Neurons via Postsynaptic H1 and H2 Receptors. Molecular neurobiology 55: 8059-8070.

Zolaly MA (2012). Histamine H1 antagonists and clinical characteristics of febrile seizures. International journal of general medicine 5: 277-281.

Figure legend

Figure 1. Histamine biosynthesis process and histamine receptors distribution and induced effects.

In the brain, the tuberomamillary nucleus neurons is the main source of histamine. Moreover, microglia also give rise to synthesize histamine, while histamine produced from cerebrovascular endothelial cells is controversial (shown in the middle). In the peripheral tissue, the mast cells and basophils in the immune system common synthesize histamine. Besides, the enterochromaffin-like cells in stomach also show the possibility to synthesis histamine (shown in the left). L-histidine was decarboxylated by HDC into histamine. Neuronal histamine was packaged into vesicles VMAT-2, and calcium release evokes histamine release from vesicles into the postsynaptic cleft, which is metabolized into tele-methyhistamine by HNMT. There are 4 histamine receptors distributed in the brain, post-synaptical H1R mediating neuronal excitation or inhibition, post-synaptical H2R facilitating neuronal excitability, and pre- or post- synaptical H3R inhibiting neuronal excitability, as well the H4R exciting neurons which is not expressed in neurons.

Figure 2. The changes of histamine in epilepsy and therapeutic effects of histamine related ligands on epilepsy.

A summary of the histamine and histamine receptor have been identified in epilepsy to date (shown in the upper). The arrow indicates up- or down-regulation, "“" indicates no change. The effect of related histamine ligands on epilepsy (shown in the lower).

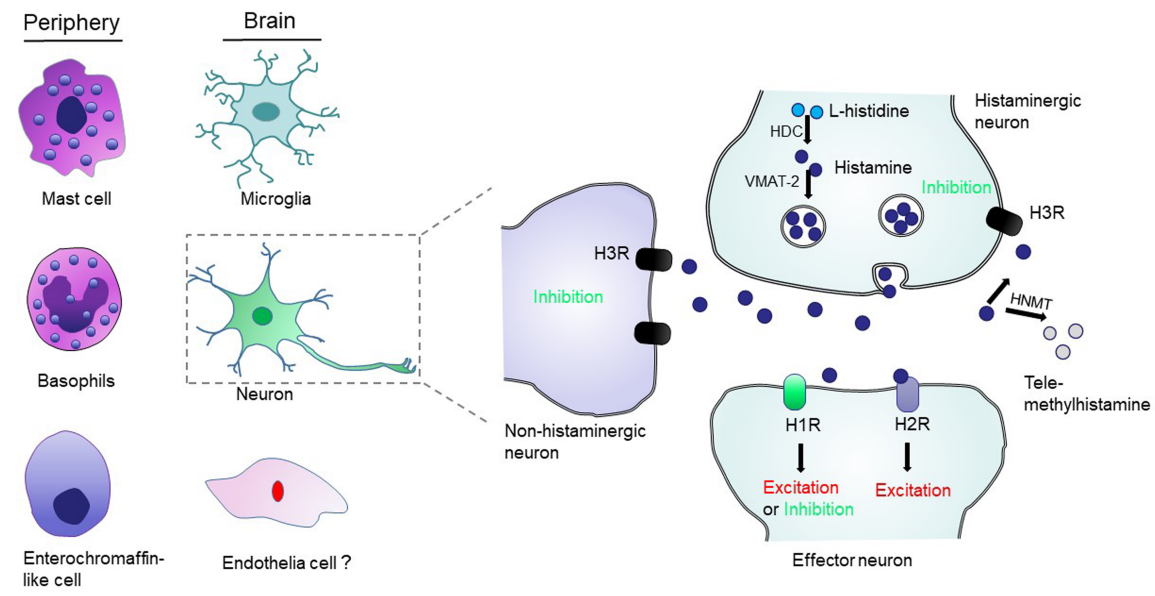




\begin{tabular}{|c|c}
\hline acute & chronic \\
\hline Histamine $(\uparrow$ or -$), \operatorname{H1R}(\downarrow)$ & Histamine $(\uparrow), \operatorname{H1R}(\downarrow), \operatorname{H} 3 \mathrm{R}(\uparrow$ or $\downarrow)$
\end{tabular}

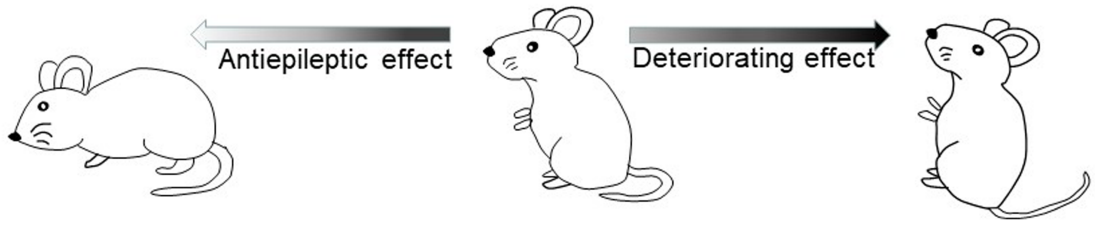

\begin{tabular}{l|l|l}
\multicolumn{1}{c}{ Antiepileptic } & \multicolumn{1}{c}{ No effect } & \multicolumn{1}{c}{$\begin{array}{c}\text { Deteriorating } \\
\text { Histamine, L-histidine, }\end{array}$} \\
$\begin{array}{l}\text { HNMT inhibitor } \\
\text { H1R/H3R antagonist }\end{array}$ & $\begin{array}{l}\text { H1R/H2R/H3R } \\
\text { antagonist }\end{array}$ & $\begin{array}{l}\text { L-histine, H1R } \\
\text { antagonist }\end{array}$ \\
H2R agonist & & \\
H1R agonist/H3R & & \\
antagonist & &
\end{tabular}

\section{Hosted file}

table1.pdf available at https://authorea.com/users/386393/articles/501803-centralhistaminergic-signaling-neural-excitability-and-epilepsy

\section{Hosted file}

table2.pdf available at https://authorea.com/users/386393/articles/501803-centralhistaminergic-signaling-neural-excitability-and-epilepsy

\section{Hosted file}

table3.pdf available at https://authorea.com/users/386393/articles/501803-centralhistaminergic-signaling-neural-excitability-and-epilepsy 